\title{
Ringed polytetrafluoroethylene (Gore-Tex) tunneled "chimney" graft for pediatric use of Impella 2.5 axial flow pump
}

\author{
Raghav Murthy, MBBS, ${ }^{a}$ Javier Brenes, MD, ${ }^{\mathrm{b}}$ Vasiliki V. Dimas, MD, ${ }^{\mathrm{b}}$ and Kristine J. Guleserian, MD, \\ Dallas, Tex
}

The Impella 2.5 axial flow pump (Abiomed Inc, Danvers, Mass) is a percutaneously placed left ventricular assist device. The device has recently gained popularity for the management of heart failure, especially in cases of acute myocarditis and post-transplant rejection because of its capability to provide short-term minimally invasive support. ${ }^{1}$ Its primary limitation for use in the pediatric population is sheath size, which remains oversized for smaller children. The Impella 2.5 is a $9 \mathrm{~F}$ catheter; however, the motor pump housing is $12 \mathrm{~F}$, requiring a $13 \mathrm{~F}$ introducer sheath for placement (Figure 1). The small size of the femoral vessels in the pediatric population lends itself to lower-extremity ischemic complications from direct sheath placement into the artery. We describe a femoral conduit technique to avoid such ischemic complications.

\section{TECHNIQUE}

Through a vertical left groin incision, the subcutaneous tissues are dissected down to the level of the femoral sheath. The common, superficial, and profunda femoral arteries are isolated proximally and distally with vessel loops. After heparinization $(100 \mathrm{U} / \mathrm{kg})$, the common femoral artery is occluded proximally and distally with straight DeBakey vascular clamps. A longitudinal femoral arteriotomy is made and a 6-mm ring reinforced polytetrafluoroethylene (Gore-Tex; WL Gore \& Associates Inc, Flagstaff, Ariz) graft is anastomosed in an end-to-side fashion using a running 6-0 Prolene suture. The graft is irrigated with heparinized saline solution. The vessel loops are sequentially released, and flow into the graft is assessed. Once hemostasis is achieved, the graft is occluded with a large hemoclip.

The ringed polytetrafluoroethylene (Gore-Tex) graft is subcutaneously tunneled to an exit site in the anterior thigh where it is secured to the skin edges with two 5-0 Prolene sutures. A $13 \mathrm{~F}$ sheath is trimmed to adequate length so

\footnotetext{
From the UT Southwestern Medical Center, ${ }^{a}$ Dallas, Tex; and Cardiovascular and Thoracic Surgery, ${ }^{\text {b }}$ University Hospital, Children's Medical Center, Dallas, Tex. Disclosures: Authors have nothing to disclose with regard to commercial support. Received for publication Aug 24, 2013; revisions received Nov 7, 2013; accepted for publication Nov 18, 2013; available ahead of print Jan 10, 2014.

Address for reprints: Raghav Murthy, MBBS, UT Southwestern Medical Center, Cardiovascular and Thoracic Surgery, University Hospital-St Paul, 9th Floor, Suite 134, 5323 Harry Hines Blvd, Dallas, TX 75390 (E-mail: raghavamurthy@ yahoo.com).

J Thorac Cardiovasc Surg 2014;147:1421-2

$0022-5223 / \$ 36.00$

Copyright (c) 2014 by The American Association for Thoracic Surgery

http://dx.doi.org/10.1016/j.jtcvs.2013.11.033
}

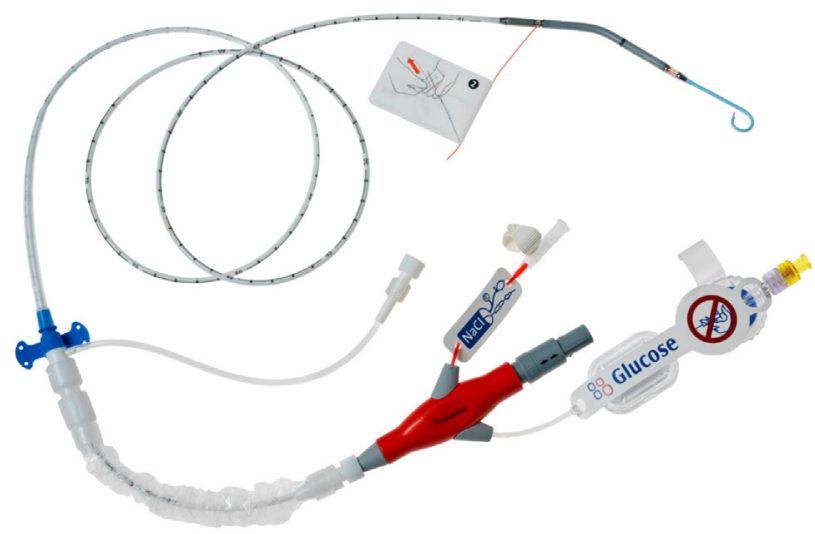

FIGURE 1. Impella 2.5 axial flow pump (Abiomed Inc, Danvers, Mass).

that the sheath length is limited to the length of the graft. The sheath is introduced into the ringed polytetrafluoroethylene (Gore-Tex) graft and secured with 0 silk (Figure 2, A). The patient shown in Figure 2, A, is an 11-year-old girl (weight $30.9 \mathrm{~kg}$, height $141 \mathrm{~cm}$, body surface area $1.1 \mathrm{~m}^{2}$ ). The common femoral artery diameter was $5 \mathrm{~mm}$. The Impella 2.5 pump is inserted into the sheath and advanced into the left ventricle under fluoroscopic guidance. The polytetrafluoroethylene (Gore-Tex) graft is stabilized at the site of the anastomosis while advancing the Impella pump. The groin incision is closed in layers in the standard fashion.

At the time of Impella removal, the ringed polytetrafluoroethylene (Gore-Tex) graft is completely excised and the artery is closed, primarily when suitable arterial diameter, or more commonly patch augmented with bovine pericardium to prevent stenosis. In this patient, at the time of Impella removal, the graft was removed and bovine pericardial patch arterioplasty was performed.

\section{DISCUSSION}

Acute myocarditis and post-transplant rejection often require short-term mechanical unloading to promote myocardial recovery. The Impella 2.5 is an intracardiac microaxial pump that is gaining popularity. The small size of the femoral vessels in the pediatric population does not lend itself to direct arterial placement of the $13 \mathrm{~F}$ outer sheath, as can be done in the adult population. From published experience in the pediatric population, direct arterial sheath placement invariably leads to distal embolic or thrombotic complications often exacerbated 

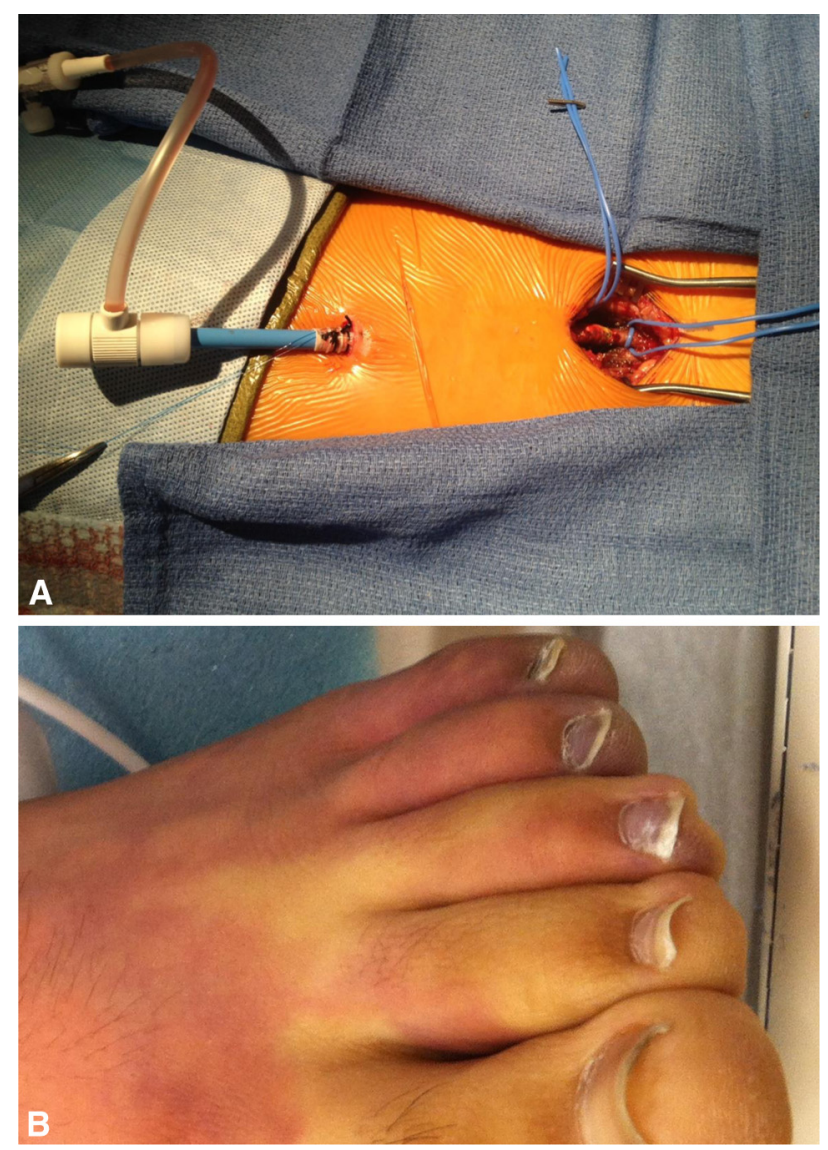

FIGURE 2. A, Tunneled ringed polytetrafluoroethylene (Gore-Tex; WL Gore \& Associates Inc, Flagstaff, Ariz) graft in place along with outer sheath for the Impella axial flow pump in position. B, Malperfused left foot (trash foot) in a 15-year-old patient with direct insertion of the Impella 2.5 into the common left femoral artery.

when vasopressor agents are used. ${ }^{2}$ Figure $2, B$, shows a patient (15-year-old male) in whom distal emboli (trash foot) developed after direct placement of an Impella 2.5 into the left femoral artery. The other vascular complications encountered include distal emboli, acute lower-extremity ischemia requiring embolectomy and revascularization, and fasciotomies. Vascular complications require device removal and may result in limb loss.

Endovascular aneurysm repair and thoracic endovascular aneurysm repair placement in the adult population are limited by atherosclerotic disease of the femoral or iliac vessels or size mismatch with the delivery systems. This challenge is often circumvented by the placement of femoral or iliac artery conduit or "chimney" grafts. ${ }^{3}$ Likewise, the axillary artery is often cannulated using a graft to help maintain cerebral circulation during cardiac surgery. ${ }^{4}$ These grafts are usually transected close to the anastomosis at the end of the procedure and oversewn or stapled off, thus leaving a small piece of graft on the artery.

Tunneling the graft into the thigh allows for a direct course for the placement of the Impella pump and avoids direct exposure of the graft to the external environment during the intensive care unit stay, theoretically decreasing the risk of graft infection. The external rings, which reinforce the graft, prevent the collapse of the graft within the subcutaneous tunnel.

\section{CONCLUSIONS}

Placement of a ring-reinforced polytetrafluoroethylene (Gore-Tex) femoral artery chimney graft is a simple technique to optimize insertion of the Impella 2.5 axial flow pump and to minimize or avoid the devastating complications of associated lower-extremity ischemia in the pediatric population.

\section{References}

1. Jefferies JL, Morales DL. Mechanical circulatory support in children: bridge to transplant versus recovery. Curr Heart Fail Rep. 2012;9:236-43.

2. Bhat TM, Waked A, Teli S, Lafferty J, Gala B. Acute complication due to Impella 2.5 device (superficial femoral artery thrombosis): managed successfully with novel aspiration thrombectomy catheter (pronto v3). Clin Med Insights Cardiol. 2011;5:17-21.

3. Peterson BG, Matsumura JS. Creative options for large sheath access during aortic endografting. J Vasc Interv Radiol. 2008;19(6 Suppl):S22-6.

4. Etz CD, Plestis KA, Kari FA, Silovitz D, Bodian CA, Spielvogel D, et al. Axillary cannulation significantly improves survival and neurologic outcome after atherosclerotic aneurysm repair of the aortic root and ascending aorta. Ann Thorac Surg. 2008;86:441-7. 